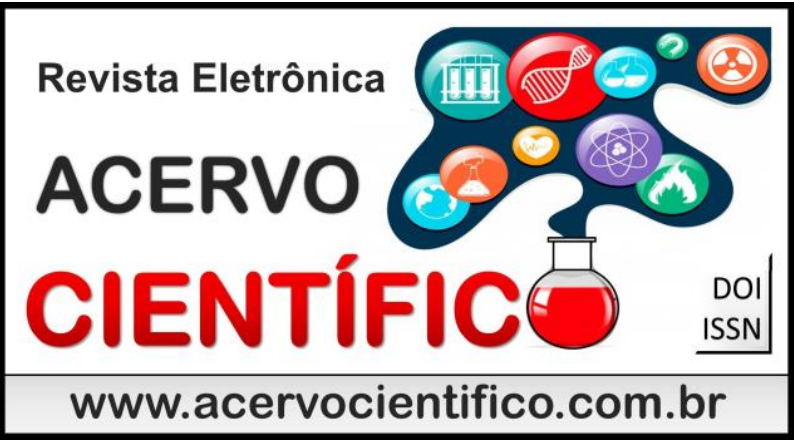

DOI: 10.25248/REAC26_2018

Recebido em: 8/2018

Aceito em: 9/2018

Publicado em: 10/2018

\title{
O papel do exercício físico na ativação de células mononucleares do Sistema Imunológico
}

The role of physical exercise in the activation of mononuclear cells of the Immune System

El papel del ejercicio físico en la activación de células mononucleares del Sistema Inmunológico

Samuel Cavalcante Reis ${ }^{1}$, Diego Andreazzi Duarte ${ }^{2}$

\begin{abstract}
Resumo: Revisar na literatura científica o papel do exercício físico (EF) no sistema imunológico (SI) e os achados sobre a importâncias desse mecanismo na atividade de células mononucleadas. Revisão bibliográfica narrativa que se deu por fundamentação teórica por meio de buscas nas bases de dados científicos Pubmed e Medline. Embora o estresse tenha sido relatado geralmente como imunosupressivo, atualmente tem-se aceitado que isto não é totalmente verdade. Neste contexto, o estresse induzido pelo exercício estimula a capacidade fagocitária de macrófagos e neutrófilos, entretanto, pouco se sabe sobre a influência do exercício físico de curta duração sobre estes parâmetros imunes, especialmente no caso do exercício leve e moderado. Tanto o EF moderado como o intenso podem acrescer diferentes funções dos mononucleados, incluindo a quimiotaxia, a aderência, a produção de superóxido, a taxa de metabolismo do nitrogênio, a atividade citotóxica e a capacidade fagocítica. Apesar dos aspectos multifatoriais e das lacunas ainda existentes, a área de investigação da imunologia do desporto, vem aumentando nos últimos anos. Toda via imunologia do exercício, conta com diversas áreas, porém, ainda não totalmente elucidadas, como por exemplo, o padrão da resposta imunológica do exercício agudo em outros tecidos. No então, várias pesquisas têm demonstrado alterações na concentração e no mecanismo de alguns componentes do SI provocadas pelo EF. As evidências disponíveis permitem concluir, que o EF tem importante efeito modulador sobre a dinâmica de células imunocompetentes, além de constante interação com o Sistema Neuroendócrino.
\end{abstract}

Palavras-chave: Atividade física, Sistema Imune, Linfócitos, Fisiologia.

Abstract: Review the role of physical exercise (EF) in the immune system (SI) and the findings about the importance of this mechanism in the activity of mononuclear cells. Narrative bibliographical review that was given by theoretical foundation through searches in the scientific databases Pubmed and Medline. Although stress has generally been reported as immunosuppressive, it has now been accepted that this is not entirely true. In this context, exercise-induced stress stimulates the phagocytic capacity of macrophages and neutrophils; however, little is known about the influence of short-term physical exercise on these immune parameters, especially in the case of mild and moderate exercise. Both moderate and high EFs may enhance different functions of mononucleates, including chemotaxis, adhesion, superoxide production, rate of nitrogen metabolism, cytotoxic activity, and phagocytic capacity. In spite of the multifactorial aspects and the still existing gaps, the area of investigation of the immunology of the sport, has been increasing in the

${ }^{1}$ Faculdades Integradas Aparício Carvalho (FIMCA), Porto Velho-RO. E-mail: samuel 2761@hotmail.com

2 Universidade Estadual de Campinas (UNICAMP), SP. E-mail: diegoandreazzi@yahoo.com.br 
last years. All via immunology of the exercise, counts on several areas, but not yet fully elucidated, as for example the response of acute exercise in other tissues. At that time, several studies have shown changes in the concentration and mechanism of some SI components caused by PE. The available evidence allows us to conclude that PE has an important modulating effect on the dynamics of immunocompetent cells, in addition to constant interaction with the Neuroendocrine System.

Key words: Physical activity, Immune system, Lymphocytes, Physiology.

Resumen: Revisar en la literatura científica el papel del ejercicio físico (EF) en el sistema inmunológico (SI) y los hallazgos sobre las cantidades de ese mecanismo en la actividad de células mononucleadas. Revisión bibliográfica narrativa que se dio por fundamentación teórica por medio de búsquedas en las bases de datos científicos Pubmed y Medline. Aunque el estrés ha sido reportado generalmente como inmunosupresivo, actualmente se ha aceptado que esto no es totalmente cierto. En este contexto, el estrés inducido por el ejercicio estimula la capacidad fagocitaria de macrófagos y neutrófilos, sin embargo, poco se sabe sobre la influencia del ejercicio físico de corta duración sobre estos parámetros inmunes, especialmente en el caso del ejercicio leve y moderado. Tanto el EF moderado como el intenso pueden añadir diferentes funciones de los mononucleados, incluyendo la quimiotaxis, la adherencia, la producción de superóxido, la tasa de metabolismo del nitrógeno, la actividad citotóxica y la capacidad fagocítica. A pesar de los aspectos multifactoriales y de las lagunas aún existentes, el área de investigación de la inmunología del deporte, viene aumentando en los últimos años.Toda vía inmunología del ejercicio, cuenta con diversas áreas, pero aún no totalmente elucidadas, como por ejemplo, el patrón de la enfermedad respuesta inmune del ejercicio agudo en otros tejidos. En el momento, varias investigaciones han demostrado cambios en la concentración y el mecanismo de algunos componentes del SI provocados por EF. Las evidencias disponibles permiten concluir, que el EF tiene un importante efecto modulador sobre la dinámica de células inmunocompetentes, además de constante interacción con el Sistema Neuroendocrino.

Palabras clave: Actividad física, Sistema Inmune, Linfocitos, Fisiología.

\section{INTRODUÇÃO}

Embora o estresse tenha sido relatado geralmente como imunosupressivo, atualmente tem-se aceitado que isto não é totalmente verdade. Neste contexto, o estresse induzido pelo exercício estimula a capacidade fagocitária de macrófagos e neutrófilos, entretanto, pouco se sabe sobre a influência do exercício físico de curta duração sobre estes parâmetros imunes, especialmente no caso do exercício leve e moderado (DUARTE DA e BRANDÃO D, 2010; FROLLINI AB, 2004).

Alterações distintas podem ser desencadear no SI em resposta a diferentes tipos e cargas de EF (HOFFMAN-GOETZ L, 2004). O EF pode ser classificado de acordo com a intensidade do esforço como: leve, moderado e intenso. Essa classificação é feita na realização de alguns testes de esforço máximo com base no consumo de oxigênio (VO2max) (LEANDRO et al., 2007). Neste sentido, é de suma importância conhecer como o exercício agudo (carga súbita de EF), moderado (entre 50 a $65 \%$ do VO2máx) ou intenso (acima de 65\% do VO2máx) podem influenciar a imunidade tanto celular como humoral (CANNON JG, 1993; KEAST D et al 1998).

Um dos primeiros estudos realizados em 1902 por Larrabee (caput, NIEMAN DC et al., 1990), o qual verificou uma leucocitose em corredores de maratona, sobretudo, aumento do número de neutrófilos na circulação. Posteriormente, a relação entre EF e SI tornou-se mais sólida a partir de observações realizadas por pesquisadores acerca do aumento da incidência de infecções respiratória do trato superior (IRTS) em atletas após treinamentos intensos ou prolongados em competições extenuantes (FORD HGW et al, 1991; MACKINNON LT e HOOPER S, 1994; NIEMAN DC et al., 1990; PYNE DB e GLEESON M, 1998; PETERS EM e BATEMAN ED, 1983). Os efeitos do EF sobre os componentes do SI são empiricamente conhecidos, porém, só recentemente estão sendo estudados os mecanismos subjacentes a estas influências.

Green KJ et al. (2002) relatam que o exercício sob condições agudas pode alterar a contagem, redistribuição, como também a capacidade funcional celular. De um modo geral, o EF agudo provoca um aumento na concentração de leucócitos na circulação (MCCARTHY DA e DALE MM, 1988). Esse fato é 
Revista Eletrônica Acervo Científico / Electronic Journal Science Collection ISSN 2595-7899

observado devido ao aumento da concentração de neutrófilos, durante e após o EF (KEAST D et al., 1988; MCCARTHY DA e DALE MM, 1988; ANGELI A et al., 2004; DA NOBREGA AC, 2005; LAGRANHA CJ et al., 2004) resultando da migração de células do tecido endotelial para o sangue ou como parte da resposta inflamatória às lesões no tecido muscular (PANNEN BH e ROBOTHAM JL, 1995; MCCARTHY DA e DALE MM, 1988; SIU PM et al., 2004).

A liberação de catecolaminas provocada pelo exercício é tida como fator mais cogitado para a indução da leucocitose e linfocitose (ARLT W e HEWISON M, 2004; MILLS PJ et al., 1999; MINETO M et al., 2005; PEDERSEN BK e HOFFMAN-GOETZ L, 2000; RONSEN O et al., 2004), provocando o recrutamento de células dos órgãos linfoides secundários como baço e linfonodos para a circulação geral (PEDERSEN BK, et al., 1997).

Aumentos nas contagens dos linfócitos, similarmente foram encontrados em ratos, tanto após protocolo agudo de natação em intensidade moderada até a exaustão, chegando até a 10 horas de exercício contínuo, como depois de protocolo agudo de corrida em esteira por 30 minutos em intensidade moderada a $60 \%$ do consumo máximo de oxigênio (VO2máx.); assim como em mulheres adultas após 30 minutos de caminhada, similarmente a $60 \%$ do VO2máx, porém já adaptadas ao exercício em questão (BERK LS et al., 1989).

Ainda, os estudos que avaliaram a redistribuição de leucócitos e linfócitos utilizando-se de modelos animais perfizeram programas de treinamento durando semanas, sendo que quando se utilizaram sessões agudas de exercícios, as pesquisas apresentaram uma variação no volume de 30 minutos até a exaustão, chegando a até 10 horas de exercício ininterrupto (MIYAZAKI H et al., 2001).

Sendo assim, o objetivo deste estudo foi revisar na literatura científica o papel do exercício físico (EF) no sistema imunológico (SI) e os achados sobre a importâncias desse mecanismo na atividade de células mononucleadas. Para tanto, foi realizada uma revisão bibliográfica narrativa que se deu por fundamentação teórica por meio de buscas nas bases de dados científicos Pubmed e Medline.

\section{EFEITO DO EXERCícIO FÍSICO NA ESTIMULAÇÃO DO SISTEMA IMUNOLÓGICO}

Os neutrófilos polimorfonucleares PMN compreendem a subpopulação de leucócitos de maior número na circulação (KEAST D et al., 1988). Suas funções nos tecidos se dão por migração na direção de partículas a serem ingeridas, denominado de quimiotaxia. Os PMN podem reconhecer, aderir e destruir inúmeros microrganismos, bactérias e vírus por fagocitose, descarregar o conteúdo de seus grânulos citoplasmáticos nos vacúolos fagocíticos por degranulação (PYNE DB, 1994). Além disso, os PMN são mediadores da lesão tecidual durante a inflamação pela liberação de espécies reativas de oxigênio e outros fatores tóxicos através da atividade oxidativa (PYNE DB et al., 1996). De Castro CB et al. (2000), afirma que a estimulação do processo fagocitário PMN durante o exercício físico é mediada pelos hormônios do estresse, principalmente catecolaminas e glicocorticoides, ambos imunosupressivo em linfócitos (BLALOCK JE, 1994; GARCIA C et al., 2003)

Apesar dos estudos sobre o efeito do EF moderado na função de PMN ainda serem conflitantes, muitos pesquisadores verificaram que o EF moderado parece auxiliar a quimiotaxia, a degranulação e a atividade oxidativa dos PMN a seguir uma hora de EF a 60\% VO2máx (MACHA M et al., 1990; MUNS G et al., 1996; ORTEGA E et al., 1973; SMITH JA et al., 2000). Entretanto, Pyne DB et al. (1996), verificaram uma diminuição na atividade oxidativa de PMN em atletas a seguir 40 (quarenta) minutos de EF aeróbico a $65 \%$ do VO2máx. Enquanto que outro estudo, verificou um aumento na atividade oxidativa de PMN tanto em atletas quanto em sujeitos não-treinados, antes e a seguir uma hora de EF a 60\% do VO2máx (SMITH JA et al., 1996). Muns G (1994), observarão um aumento da atividade fagocítica dos PMN em homens treinados 24 (vinte e quatro) horas a seguir uma corrida de $20 \mathrm{~km}$ a $60 \%$ do VO2máx. Por outro lado, Ortega E et al. (1993), não encontraram alteração significantes na atividade fagocítica de PMN após uma hora de atividade aeróbica a 50\% do VO2máx em homens sedentários. A justificativa para os diversos resultados encontrados pode estar nos diferentes protocolos experimentais utilizados (ROSA LFPBC e VAISBERG MW, 2002). 
Diferente do EF moderado, os estudos referentes à resposta funcional de PMN ao EF intenso são mais consistentes. Porém, as funções dos PMN parecem diminuir a seguir um EF intenso (SMITH JA e PYNE DB, 1997; WOODS JA et al. 1999). Alguns estudos demonstram que a capacidade oxidativa destas células é atenuada durante e após uma carga aguda de EF intenso (>85\% do VO2máx) (HACK V et al., 1992; PYNE DB, 1994; PYNE DB, et al., 2000; SMITH JA et al., 1990; SCHULENBURG H et al., 2004). Entre outras, Bury TB et al., (1996), verificaram diminuição na função fagocítica de neutrófilos em futebolistas no período de competição.

O estudo de Robson PJ et al. (1999), ao comparar o efeito de um EF a 80\% VO2máx durante uma hora, com um EF a 55\% VO2máx durante 3 horas em indivíduos treinados, verificou, aumento similar na contagem de PMN nas duas intensidades durante e a seguir o esforço físico. Curiosamente, o mesmo estudo evidenciou diminuição da atividade oxidativa e anti-bactericida mais evidente a seguir o EF moderado, possibilitando concluir que as alterações nas funções dos neutrófilos parecem ser dependentes não somente da amplitude, mas também da duração do esforço. Seguindo a mesma afirmação, para Pedersen BK e Bruunsgaard H (1995) no exercício intenso a imunossupressão é apenas evidente quando o EF é intenso e de longa duração, 60 min ou mais. Ademais, ainda são necessários estudos que investiguem a significância fisiológica das alterações funcionais do EF e SI a esse tipo celular.

Além dos polimorfonucleares, no que se referem a outros tipos de celulares presentes nos tecidos, os linfócitos teciduais encontram em constante balanço com os plasmáticos, percorrendo continuamente por meio de vasos linfáticos e vasculares (KENDALL A et al., 1990). Durante o EF agudo, moderado ou intenso ocorre o aumento da concentração plasmática destas células, decorrido do recrutamento de todas as suas populações (células natural killer (NK), linfócitos $T$ e linfócitos $B$ ), constituindo uma resposta culminantemente estereotipa (PANNEN BH e ROBOTHAM JL, 1995; PEDERSEN KB e HOFFMAN-GOETZ L, 2000). No entanto, durante o exercício, é verificado um aumento de linfócitos em cerca de $50 \%$ a $100 \%$ em relação ao valor basal. No período de recuperação (30 minutos após o exercício), a contagem de linfócitos diminui de $30 \%$ a 50\%, que perdura durante 3 a 6 horas (PEDERSEN KB e HOFFMAN-GOETZ L, 2000).

Entre as populações de linfócitos, as células NK são conhecidas por desencadear defesa precoce contra certas infecções intracelulares sem necessidade prévia de imunização ou ativação (VAN DEN BERGH $P$, et al., 1993). As células NK são responsáveis pela exterminação de células tumorais e células infectadas por vírus através de atuação citolítica. Além disso, essas células são as que mais demonstram alterações decorrentes do EF, quando comparadas aos demais tipos celulares. Sabe-se que vários tipos de exercícios, independentemente de sua duração e intensidades induzem o recrutamento de células NK para o sangue, deste modo, provocando alterações na atividade citolítica destas células (BERK LS et al., 1989; VAN DEN BERGH P et al., 1993).

Tvede $\mathrm{N}$ et al. (1993) analisou a resposta de linfócitos em ciclistas durante uma hora de EF em três diferentes intensidades de esforço (25\%,50\% e $75 \%$ do VO2máx). Os autores verificaram, neste estudo, linfocitose seguida de linfopenia, observadas durante o EF em duas intensidades, 50\% e 75\% do VO2máx. O experimento verificou ainda que a atividade citolítica de células NK e da linfocina ativadora de células NK (LAK) acresceu durante todo esforço e foi suprimida 2 horas após seguir o EF a $75 \%$ do VO2máx. Em atletas não-competitivos após um período de treinamento de 8 meses, a atividade citotóxica de células NK também parece aumentar (MACKINNON LT, 2000).

No período imediato pós-esforço as células NK, apresentam aumento de 150 a 300\% a nível sanguíneo periférico, sendo presumível que este mecanismo se deva ao grande número de receptores $\beta$-adrenérgicos em sua membrana celular. Esse acréscimo é temporário, retornando aos os níveis pré-exercício após 30 minutos, possivelmente por ação do cortisol. No entanto, a seguir 2 horas de EF intenso (>75\% VO2máx), a concentração de células NK diminui em cerca de 25 a 40\% do nível basal, podendo prolongar por até 4 horas a pós-esforço (KLOKKER $\mathrm{M}$ et al., 1995; PEDERSEN BK et al.,1989; PEDERSEN BK e BRUUNSGAARD H, 1995). Nesse sentido, outro estudo verificou que o EF fadigante em atletas treinados também sugere diminuição na função citolítica das células NK (NIEMAN DC et al., 1995). Seguindo e mesmo princípio, alguns pesquisadores observaram queda da atividade citolítica destas células em atletas 
após um EF muito intenso de curta duração (6 min) (NIELSEN HB et al., 1994). Contudo, essas alterações funcionais da célula NK são bastante evidentes, tanto em atletas jovens como em idosos (KLOKKER $\mathrm{M}$ et al., 1995; LANDMANN R et al., 1984). Essas evidências estão fortemente relacionadas à diminuição da taxa de gordura corporal e também a aumento da secreção de $\beta$-endorfinas. Esses achados sugerem que a intensidade parece ser responsável pelo aumento plasmático e pelas alterações funcionais de células NK (ROSA LFPBC e VAISBERG MW, 2002).

O EF também interfere na concentração de outras populações de linfócitos76. Os linfócitos $T$ são divididos em duas subpopulações: células T auxiliares (CD4+) e células T citotóxicas (CD8+). As células T CD8+, dentre outras funções, atuam na destruição de células infectadas por vírus ou de células tumorais. Enquanto que as células T CD4+ além de estimulação, proliferação e maturação de linfócitos $B$, são responsáveis pela libertação de LAK (KEAST D et al., 1988).

Quando analisado, o EF a $50 \%$ do VO2máx, os dados são conflitantes, parece não alterar a concentração de células T CD4+ e T CD8+ (MACKINNON LT et al., 1987; PEDERSEN KB e HOFFMANGOETZ L, 2000; TVEDE N et al., 1991; TVEDE N et al., 1993). Alguns estudos têm observado que um EF a $75 \%$ do VO2máx tende a causar uma queda na concentração de células T CD4+, sem interferir na concentração de células T CD8+. Desse modo, os níveis de células CD4+/CD8+ diminui propondo aumento de células T CD8+ em resposta a um EF intenso (BERK LS et al., 1989; FRY RW et al., 1992; PEDERSEN KB e HOFFMAN-GOETZ L, 2000). Esse processo é decorrente, principalmente, pela ação da epinefrina e do cortisol.

Lin YS et al. (1993) observaram em seu estudo que animais previamente submetidos a 10 semanas de corrida moderada a 70\% do VO2max, tiveram diminuição das subpopulações de linfócitos $\mathrm{T}$, da proliferativa de linfócitos B do baço e dos níveis plasmáticos de IL-2. Enquanto que, Fu SC et al., (2003) mostraram que o EF moderado com duração de 4 semanas previne a diminuição de linfócitos TCD4+ no plasma.

Em outro estudo, realizado em modelo in vitro com células humanas, a administração de epinefrina foi capaz de reduzir a atividade de linfócitos a mitógenos, mais especificamente verificou-se que a epinefrina atua pela sensibilização de receptores $\beta_{2}$-adrenérgicos, o que ocasiona em um feedback negativo na proliferação de linfócitos, síntese de IL-2 e aumento da expressão de receptores para IL-225. O cortisol sugere também bloquear a proliferação celular por ação direta e por inibição da síntese de IL-219. Outro mecanismo de inibição das células linfocitárias pode estar na atenuação por monócitos na expressão do MHC de classe II (GOMEZ-MERINO D et al., 2005).

O EF também parece ser determinante na resposta proliferativa de linfócitos, dependente da duração e intensidade. A fim de verifica essas alterações, alguns autores ao submeter um EF $(50 \%$ e $75 \%$ do VO2máx) com duração de uma hora, propuseram diminuição dessas células no período pós-esforço (TVEDE N et al., 1991; TVEDE N et al., 1993). Contudo, não foi encontrada alteração na proliferação de linfócitos a seguir um EF de resistência de força (NIEMAN DC et al.,1995).

Outro importante fator imune, as citocinas, são hormônios proteicos, mediadores e reguladores de respostas do $\mathrm{SI}$ e inflamatórias, produzidas pelas próprias células de defesa, durante as fases de ativação da imunidade inata e específica (PITANGA FJG, 2002). Estudos recentes têm concluído que a imunidade inata aumenta com o EF agudo, protegendo o organismo de infecções (FROLLINI AB, 2004).

Curiosamente, a interleucina-2 (IL-2) é uma das citocinas que tem sido utilizada como estimulante dos linfócitos e ainda das células NK (PEDERSEN BK et al, 1997). Contudo, a IL-2 por sua vez, é sintetizada pelos linfócitos $T$ citotóxicos e posteriormente elas irão agir na proliferação e ativação dos linfócitos $T$ por CD4 e CD6, objetivando a morte viral juntamente com as células NK que foram estimuladas pelo IFN-3 (OLIVEIRA CAM et al , 2002) Além disso, a IL-2 ativa os monócitos/macrófagos e a liberação de outras citocinas como TNF- \pm e IFN-3. . (FEREIRA CKO et al., 2007).

Além das citocinas, a seguir um EF intensos e de longa duração ocorre alterações imunomoleculares das imunoglobulinas, um declínio de cerca de $70 \%$ dos níveis salivar de imunoglobulina A ( $\lg A)$, é originado, persistindo por inúmeras horas pós-esforço (MACKINNON LT et al., 1987). As imunoglobulinas (lg), da 
classe das glicoproteínas, são secretadas por linfócitos. Elas combinam-se com especificidade a antígenos induzindo a produção da resposta imune humoral (PEDERSEN KB e HOFFMAN-GOETZ L, 2000). Dentre os subgrupos, a IgA constitui 10 a $15 \%$ do total de imunoglobulinas, sendo a principal classe de anticorpo das mucosas (Robson PJ et al., 1998).

Blannin et al6 verificaram queda das concentrações de IgA a seguir um EF aeróbico a $65 \%$ do VO2máx. Contrariamente, alguns autores descrevem a inexistência de alterações do nível salivar de $\lg A$ e $\operatorname{de} \operatorname{lgE}$ durante um EF moderado (MACKINNON LT e HOOPER S, 1994; NIEMAN DC et al., 1990). Outros estudos, verificaram também queda na concentração de IgA após um EF intenso de longa duração, tanto salivar quanto da mucosa nasal (MACKINNON LT e HOOPER S, 1994; NEHLSEN-CANNARELLA SL, 1998; NIEMAN DC et al., 1990). Seguindo esse princípio, os pesquisadores correlacionaram a redução da IgA com a prevalência de ITRS em atletas (Nieman DC et al., 1990).

Estudos epidemiológicos comprovam uma grande ocorrência de ITRS em atletas a seguir uma prova ou um treinamento intenso (CANNON JG, 1993; FITZGERALD L, 1991; FORD HGW et al., 1991; NIEMAN DC et al., 1990), entretanto, um estudo verificou existência de sintomas de ITRS em somente $33,3 \%$ dos maratonistas, enquanto que no grupo controle o índice foi de 15.3\% (PETERS EM e BATEMAN ED, 1983). Ainda que os estudos revelem um aumento dos sintomas de ITRS a seguir um EF intenso e de extensa duração, não é evidente se esses sintomas são decorrentes do processo infeccioso em si, ou se são resultantes de uma inflamação local ou sistêmica causada pelo EF (PEDERSEN KB e HOFFMAN-GOETZ L, 2000).

Enquanto o exercício moderado regular é comumente associado com a diminuição da susceptibilidade a infecções, o exercício exaustivo de longa duração tem sido associado com sintomas de imunossupressão transitória, com aumento da susceptibilidade a infecções (MATSUDO VHR e MASHECHA SM, 2002). Essas respostas são altamente dependentes da habilidade dos leucócitos em migrarem do sangue para os tecidos periféricos em locais de inflamação. A migração, rolamento, ativação e forte adesão dos leucócitos compreendem o clássico paradigma do recrutamento inflamatório celular (LEANDRO C et al., 2006).

\section{ATIVIDADE DE MONONUCLEADOS EM RESPOSTA AO EXERCÍcIO FÍSICO}

Quando consideramos outra linhagem de células fagocíticas como os mononucleados, monócitos e macrófagos, independente da intensidade e da duração, o EF agudo sugere uma monocitose transitória. Por outro lado, apesar da apuração de macrófagos nos tecidos em resposta a um EF ser relativamente inacessível em humanos, o stress provocado pelo EF sugere ter um efeito estimulador na função de macrófagos (FIELD CJ et al., 1991; WOODS JA, 1999; BLALOCK JE, 1994; GARCIA C et al., 2003; BESEDOVSKY HO e DEL REY A, 2002).

Além de indispensáveis células efetoras, os fagócitos mononucleares estão envolvidos na fagocitose e na atividade antimicrobiana e antitumoral por meio de mecanismo acessório como apresentadores antigênicos, responsável pelo subsequente desenvolvimento da imunidade mediada por linfócito (WOODS JA et al., 1997; WOODS JA et al., 1999). Esse tipo celular é regulado por sinalizadores químicos que são produzidos pelo SNS, pelo eixo HPA e por outras células de origem linfoide (GARCIA C et al., 2003; BESEDOVSKY HO e DEL REY A, 2002). Os fagócitos mononucleares são também uma fonte de citocinas mediadoras das reações inflamatórias e fisiopatológicas da lesão celular (WOODS JA et al.,1999).

Tanto o EF moderado como o intenso podem acrescer diferentes funções dos mononucleados, incluindo a quimiotaxia, a aderência, a produção de superóxido, a taxa de metabolismo do nitrogênio, a atividade citotóxica e a capacidade fagocítica (FIELD CJ et al., 1991 ; NEHLSEN-CANNARELLA SL, 1998; ORTEGA E et al., 1997; WOODS JÁ et al., 1994; VAN DEN BERGH P et al., 1993; WOODS JA et al., 1999). Além disso, foi confirmado também, aumento da capacidade antitumorais de macrófagos peritoneais, possivelmente decorrente da maior produção de TNFa e de óxido nítrico. Os mecanismos envolvidos a estas respostas ainda não foram elucidados, apesar poder estar associados a fatores neuroendócrinos (VAN DEN BERGH P et al., 1993; WOODS JÁ et al.,1999; PEDERSEN BK et al., 1997; ROSA LFP E VAISBERG MW, 2002). 
O papel mediador dos glicocorticoides pode também diferir nas funções não específicas dos macrófagos, como a quimiotaxia e a fagocitose, assim como também, aquelas mais específicas como apresentação de antígenos. O exercício extenuante diminui o número de macrófagos peritoneais em ratos, e a magnitude deste efeito é positivamente correlacionada com a concentração de corticosterona plasmática (ESCRIBANO $\mathrm{BM}$ et al., 2005) Além disso, neutrófilos e monócitos podem ser estimulados por catecolaminas ou sinais simpáticos (FROLLINI AB, 2004). Ortega $E$ et al. (1996), evidenciou em seu estudo que as variações na fagocitose e catecolaminas têm sido propostas como um bom marcador neuro-imuno endócrino em atletas. Outros hormônios como os da tireoide, prolactina, GH e endorfinas contribuem em geral nos efeitos do estresse ao exercício agudo sobre a fagocitose (WOODS JA, 1999).

Uma pesquisa evidenciou aceleração no processo fagocítico de macrófagos peritoneais de ratos submetidos à natação até a exaustão ou submetidos ao treino (90 minutos de nado durante 20 dias) (FERRANDEZ MD e DE LA FUENTE M, 1999). Seguindo o mesmo protocolo de EF, um estudo demonstrou que os animais submetidos à natação durante 6 semanas previamente a uma situação de estresse apresentaram alteração no perfil leucocitário comparativamente aos animais sedentários e estressados (NASCIMENTO E et al.,2004).

Estudos mostram que o exercício com duração de até 15 minutos em intensidade leve pode melhorar a função imune por meio do aumento da capacidade fagocitária (FERREIRA CKO et al., 2007). Woods JA et al. (1994), verificaram que tanto uma corrida exaustiva em esteira (18 a $35 \mathrm{~m} / \mathrm{min}$ há $5 \%$ de inclinação durante 2 a 4 h) quanto uma moderada (18 $\mathrm{m} / \mathrm{min}$ há $5 \%$ de inclinação durante $30 \mathrm{~min}$ ) é capaz de provocar o aumento da citotoxicidade antitumoral de macrófagos peritoneais. No entanto, os mesmos autores também verificaram que o EF muito aturado e de pequena duração, em camundongos, levou a um decréscimo na capacidade de apresentação antigênica de macrófagos peritoneais. Em contra partida, Davis JM et al.(1997), constataram que um EF exaustivo de extensa permanência (2.5-3.5 h) pode gerar diminuição na atividade de macrófagos alveolares e acrescer a susceptibilidade de infecções em ratos.

Os estudos acerca das alterações funcionais dos mononucleados ao EF ainda são insuficientes para afirmar a reação celular tecidual, devido aos diversos tipos de intensidade e duração do EF, portanto, se vê a necessidade da realização de estudos comprobatórios, em particular a esse tipo de células. Acredita-se que o sistema monócitos/macrófagos podem depender do protocolo de EF, assim como da localização anatômica para a expressão de seu fenótipo funcional (HAAHR PM et al., 1991).

As alterações ao exercício agudo, podendo ser compreendidas como resposta ao estresse. Assim, fica claro que, apesar de temporárias, tais mecanismos podem adquirir grande importância em consequência a quedar de determinadas funções imune em resposta a EF de alta intensidade. No entanto, mesmo frente a estímulos de alta amplitude, a resposta de polimorfonucleados e mononucleados se mantém elevada (ROSA LFP e VAISBERG MW, 2002).

Segundo Leandro C et al.(2002), uma nova interpretação fisiológica está emergindo acerca da estimulação geral da fagocitose e outros mecanismos durante o EF extenuante, que independente a duração, pode contrabalancear a diminuição da atividade linfoide, prevenindo a entrada e sobrevivência de microrganismos em situações onde as respostas específicas são suprimidas.

Não obstante, muitos aspectos existentes entre EF e imunidade ainda não foram completamente elucidados. No entanto, diversos fatores como período e intensidade do esforço, resposta imunológica, estado psicológico, capacidade física e nutricional, além de influências climáticas e os antecedentes alérgicos e inflamatórios no trato respiratório, devem ser levados em consideração, ao avaliar o parâmetro imunológico em resposta ao EF (MACKINNON LT, 1998).

\section{CONSIDERAÇÕES FINAIS}

Toda via imunologia do exercício, conta com diversas áreas, porém, ainda não totalmente elucidadas, como por exemplo, o padrão da resposta imunológica do exercício agudo em outros tecidos. No então, várias pesquisas têm demonstrado alterações na concentração e no mecanismo de alguns componentes do SI provocadas pelo EF. As evidências disponíveis permitem concluir, que o EF tem importante efeito 
modulador sobre a dinâmica de células imunocompetentes, além de constante interação com o Sistema Neuroendócrino.

Apesar dos aspectos multifatoriais e das lacunas ainda existentes, a área de investigação da imunologia do desporto, vem aumentando nos últimos anos. O grande desafio dos pesquisadores, portanto, seria estabelecer um modelo experimental baseado na intensidade, duração e frequência nos diferentes tipos de esforço físico de forma a instituir o binômio exercício/saúde.

\section{REFERÊNCIAS}

1. ANGELI A, MINETTO M, DOVIO A et al. The overtraining syndrome in athletes: a stress-related disorder. J Endoc. Invest. 2004;27:603-12.

2. ARLT W, HEWISON M. Hormones and immune function: implications of aging. Aging Cell, Oxford. 2004;v.3, n.4, p.209-16.

3. BESEDOVSKY HO, DEL REY A. Regulating inflammation by glucocorticoids. Nat Immunol. 2006;7:537.

4. BERK LS, NIEMAN DC, TAN SA. Maximal exercise modifies lymphocytes and subpopulations T helper and T suppressor and ratio in man. Med Sci Sports Exercise. 1989;19:43-44.

5. BESEDOVSKY HO, DEL REY A. Introduction: immune-neuroendocrine network. Front Horm Res. 2002;29:1-14.

6. BLALOCK JE. The syntax of immune-neuroendocrine communication. Immunol Today. 1994;15:504-11.

7. BURY TB, LUIS R, RADERMAKER MF. Pirnay F. Blood mononuclear cells mobilization and cytokine secretion during prolonged exercises. Int J Sports Med; 1996;17: 156-160.

8. CANNON JG. Exercise and resistance to infection. J Appl Physiol. 1993;74: 973-981.

9. DAVIS JM, KOHUT ML, HERTLER-COLBERT M et al. Exercise, alveolar macrophage function, and susceptibility to respiratory infection. J Appl Physiol. 1997; 83:1461-1466.

10. DA NOBREGA AC. The subacute effects of exercise: concept, characteristics, and clinical implications. Exerc Sport Sci Rev. 2005;33:7-84.

11. DE CASTRO CB, MANHÃES-DE-CASTRO R, MEDEIROS AF et al. Effect of stress on the production of O2 - in alveolar macrophages. J Neuroimmunol. 2000;108 (1) 68-72.

12. DUARTE DA E MELO-ALMEIDA MG. Aspectos Moleculares do Sistema Imunológico no Envelhecimento. REAS, Revista Eletrônica Acervo Saúde. 2010;1:01-10.

13. DUARTE DA E BRANDÃO D. Achados Sobre a Influência do Exercício Físico na Fisiologia Imunitária. REAS, Revista Eletrônica Acervo Saúde. 2010;1:10-18.

14. ESCRIBANO BM, CASTEJON FM, VIVO $R$ et al. Effects of training on phagocytic and oxidative metabolism of peripheral neutrophils in horses exercised in the aerobic-anaerobic transition area. Vet Res Commun. 2005;29(2):1,49-58.

15. FERRANDEZ MD, DE LA FUENTE M. Effects of age, sex and physical exercise on the phagocytic process of murine peritoneal macrophages. Acta Physiol Scand. 1999;166(1):47-53.

16. FERREIRA CKO. Influência do exercício físico agudo sobre a resposta inata de macrófagos e neutrófilos de ratos sedentários. [MONOGRAFIA] Universidade Federal de São Paulo, 2003.

17. FEREIRA CKO, PRESTES J, DONATTO FF et al. Efeitos agudos do exercício de curta duração sobre a capacidade fagocitária de macrófagos peritoneais em ratos sedentários. Rev. bras. fisioter, São Carlos, v. 11, n. 3, p. 191-197, maio/jun. 2007.

18. FIELD CJ, GOUGEON R, MARLISS EB. Circulating mononuclear cell numbers and function during intense exercise and recovery. $J$ Appl Physiol. 1991;71: 1089-1097.

19. FROLLINI AB. Influencia do Exercício Físico Leve e Moderado Agudo e após a Adaptação sobre a Produção de Citocinas em Cultura de Linfocitos de Ratos. [MONOGRAFIA] Universidade Federal de São Paulo, 2004.

20. FITZGERALD L. Overtraining increases the susceptibility to infection. Int J Sports Med. 1991;12: 55-58.

21. FORD HGW, CRAVEN TE, MACERA CA et al. Exercise and the incidence of upper respiratory tract infections. Med Sci Sports Exercise. 1991;23: 152-157.

22. FRY RW, MORTON AR, CRAWFORD GP et al. Cell numbers and in vitro responses of leukocytes and lymphocyte subpopulations following maximal exercise and interval training sessions of different intensities. Eur J Appl Physiol. 1992;64:218-227.

23. GARCIA C, DE OLIVEIRA MC, VERLENGIA R et al. Effect of dexamethasone on neutrophil metabolism. Cell Bioch. Funct. 2003;21:105-11.

24. GREEN KJ, ROWBOTTOM DG, MACKINNON LT. Exercise and T-lymphocyte function: a comparison of proliferation in PBMC and NK celldepleted PBMC culture. Journal of Applied Physiology, Bethesda, v.92, n.6, p.2390-5, 2002.

25. GOMEZ-MERINO D, DROGOU C, CHENNAOUI $M$ et al. Effects of combined stress during intense training on cellular immunity, hormones and respiratory infections. Neuroimmunomodulation. 2005;12:164-72.

26. HAAHR PM, PEDERSEN BK, FOMSGAARD A et al. Effect of physical exercise on in vitro production of interleukin 1, interleukine 6 , tumor necrosis factor-a, interleukin 2 and interferon-g. Int J Sports Med. 1991;12: 223-227.

27. HACK V, STROBEL G, RAU JP et al. The effect of maximal exercise on the activity of neutrophil granulocytes in highly trained athletes in a moderate training period. Eur J Appl Physiol. 1992;65: 520-524.

28. HOFFMAN-GOETZ L, DUERRSTEIN L. The effect of chronic and acute exercise on thymocyte apoptosis and necrosis in ovariectomized mice given dietary genistein. J Sports Med Phys Fitness. 2004;44:281-7.

29. KEAST D, CAMERON K, MORTON AR. Exercise and the immune response. Sports Med. 1988;5: 248-267

30. KLOKKER M, KJAER M, SECHER NH. Natural killer cell response to exercise in humans: effect of hypoxia and epidural anesthesia. J Appl Physiol. 1995;78: 709-716.

31. LAGRANHA CJ, DE LIMA TM, SENNA SM. The effect of glutamine supplementation on the function of neutrophils from exercised rats. Cell Biochem Funct. 2005:23:101-7.

32. LANDMANN R, MULLER FB, PERINI CH et al. Changes of immune-regulatory cells induced by psychological and physical stress: relation to catecholamines. Clin Exp Immunol. 1984;58: 127-135.

33. LEANDRO CG, MARTINS DE LIMA T, FOLADOR A et al. Physical training attenuates the stress-induced changes in rat t-lymphocyte function. Neuroimmunomodulation. 2006:13:1,05-13.

34. LEANDRO C, NASCIMENTO E, CASTRO RM et al. Exercício físico e sistema imunológico: mecanismos e integrações. Revista Portuguesa de Ciências do Desporto, 2002, vol. 2, no 5: 24-30.

35. LEANDRO CG, CASTRO RM, NASCIMENTO E et al. Mecanismos adaptativos do sistema imunológico em resposta ao treinamento físico. Rev Bras Med Esporte_Vol. 13, № 5 - Set /Out, 2007

36. LIN YS, JAN MS, CHEN HI. The effect of chronic and acute exercise on immunity in rats. Int J Sports Med. 1993;14:86-92.

37. MACHA M, SHLAFER M, KLUGER MJ. Human neutrophil hydrogen peroxide generation following physical exercise. J Sports Med Phys Fitness. 1990;30:412-419.

38. MACKINNON LT, CHICK TW, VANAS A et al. The effect of exercise on secretary and natural immunity. Adv Exp Med Biol.1987;216: 869-76

39. MACKINNON LT. Chronic exercise training effects on immune function. Med Sci Sports Exerc. 2000;32:3,69-76. 
40. MACKINNON LT. Future directions in exercise and immunology: regulation and integration. Int. J. Sports. Med. 1998; 19:205-211.

41. MACKINNON LT, HOOPER S. Mucosal (secretory) immune system responses to exercise of varying intensity and during overtraining. Int $\mathrm{J}$ Sports Med. 1994;15 suppl:179-183.

42. MATSUDO VHR, MASHECHA SM. Câncer e exercício: uma revisão. Rev. bras. ciênc. mov, 2002 ;6(2):41-6.

43. MCCARTHY DA, DALE MM. The leucocytosis of exercise. A review and model. Sports Med. 1988;6: 333-363.

44. MILLS PJ, REHMAN J, ZIEGLER MG. Nonselective? Blockade attenuates the recruitment of CD62L T lymphocytes following exercise. European Journal of Applied Physiology and Occupational Physiology, Berlin. 1999;v.79, n.6, p.531-4

45. MINETO M, RAINOLDI A, GAZZONI M et al. Differential responses of serum and salivary interleukin-6 to acute strenuous exercise. European Journal of Applied Physiology, Berlin. 2005;v.93, n.5-6, p.679-86.

46. MIYAZAKI H, OH-ISHI S, OOKAWARA T et al. Strenuous endurance training in humans reduces oxidative stress following exhausting exercise. Eur J Appl Physiol. 2001;84:1-6.

47. MUNS G. Effect of long-distance running on polymorphonuclear neutrophil phagocytic function of the upper airways. Int $J$ Sports Med. 1994;15(2):96-99.

48. MUNS G, RUBINSTEIN I, SINGER P. Neutrophil chemotactic activity is increased in nasal secretions of long-distance runners. Int J Sports Med. 1996;17(1):56-59.

49. NASCIMENTO E, CAVALCANTE T, PEREIRA S et al. O exercício físico crônico altera o perfil leucocitário e a taxa de fagocitose de ratos estressados. Revista Portuguesa de Ciências do Desporto. 2004;4,3:26-33.

50. NEHLSEN-CANNARELLA SL. Cellular responses to moderate and heavy exercise. Can J. Physiol Pharmacol. $1998 ; 76$ (5): $485-489$.

51. NIEMAN DC, JOHANSSEN LM, LEE JW et al. Infections episodes in runners before and after the Los Angeles Marathon. J Sports Med Phys Fitness. 1990;30: 316-328.

52. NIEMAN DC, HENSON DA, SAMPSON CS et al. The acute immune response to exhaustive resistence exercise. Int $J$ Sports med. 1995; $16: 322-328$.

53. NIEMAN DC, NEHLSEN CSL. The immune response to exercise. Semin Hematol 1994:31:166-79.

54. OLIVEIRA CAM, ROGATTO GP, LUCIANO E. Efeitos do treinamento físico de alta intensidade sobre os leucócitos de ratos diabéticos. Rev Bras Med Esporte. 2002;8,6.:219-224.

55. ORTEGA E, BARRIGA C, DE LA FUENTE M. Study of the phagocytic function of neutrophils from sedentary men after acute moderate exercise. Eur J Appl Physiol. 1993;66:60-64.

56. ORTEGA E, FORNER MA, BARRIGA C. Effect of betaendorphin on adherence, chemotaxis and phagocytosis of Candida Albicans by peritoneal macrophages. ComplImmunol Microbiol Infect Dis. 1996;19(4):267-74.

57. ORTEGA E, FORNER A, BARRIGA C. Exercise-induced stimulation of murine macrophage chemotaxis: role of corticosterone and prolactine as mediators. J Physiol (Lond). 1997;498:729-734.

58. PANNEN BH, ROBOTHAM JL. The acute-phase response. Ne Horizons. 1995;3: 183-197.

59. PEDERSEN BK, BRUUNSGAARD H. How physical exercise influences the establishment of infections. Sports Med. 1995;19:193-400.

60. PEDERSEN BK, BRUUNSGAARD H, KLOKKER M et al. Exercise induced immunomodulation: possible roles of neuroendocrine factors and metabolic factors. Int J Sports Med. 1997;18 Suppl:2-7.

61. PEDERSEN KB, HOFFMAN-GOETZ L. Exercise and the immune system: regulation, integration and adaptation. Physiol Rev. 2000;80 (3): 1055-1081.

62. PETERS EM, BATEMAN ED. Ultra marathon running and upper respiratory tract infections: An epidemiological survey. South African Mel J. 1983:64, 582-584

63. PITANGA FJG. Epidemiologia, atividade física e saúde. Rev. Bras. Ciên. e Mov. 2002, v.10 n. 3 p.

64. PYNE DB. Regulation of neutrophil function during exercise. Sports Med, 1994 17(4):245-58.

65. PYNE DB, BAKER MS, SMITH JA et al. Exercise and the neutrophil oxidative burst: biological and experimental variability. Eur J Appl Physiol Occup Physiol. 1996;74(6):564-71.

66. PYNE DB, GLEESON M. Effects of intensive exercise training on immunity in athletes. Int J Sports Med. 1998;19: 138-194.

67. PYNE DB, SMITH JA, BAKER MS et al. Neutrophil oxidative activity is differentially affected by exercise intensity and type. J Sci Med Sport. 2000;3(1):44-54.

68. ROBSON PJ, BLANNIN AK, WALSH NP et al. Effects of exercise intensity, duration and recovery on in vitro neutrophil function in male athletes. Int J Sports Med. 1999;20: 128-135.

69. RONSEN O, BORSHEIM E, PEDERSEN BK et al. Immunoendocrine and metabolic responses to long distance ski racing in world class male and female cross-country skiers. Scandinavian Journal of Medicine \& Science in Sports, Copenhagen. 2004;v.14;1:39-48.

70. ROSA LFP, VAISBERG MW. Influências do exercício na resposta imune. Rev Bras Med Esporte. 2002;8:4;jul/ago.

71. SCHULENBURG H, KURZ CL, EWBANK JJ. Evolution of the innate immune system: the worm perspective. Immunol Rev. 2004:198:36-58.

72. SIU PM, BRYNER RW, MARTYN JK et al. Apoptotic adaptations from exercise training in skeletal and cardiac muscles. Faseb J. 2004;18:1150-2.

73. SMITH JA, GRAY AB, PYNE DB et al. Moderate exercise triggers both priming activation of neutrophil subpopulations. Am J Physiol. 1996;270:838-845.

74. SMITH JA, PYNE DB. Exercise, training, and neutrophil function. Exerc Immunol Rev. 1997;3:96-116.

75. SMITH LL, ANWAR A, FRAGEN M et al. Cytokines and cell adhesion molecules associated with high-intensity eccentric exercise. Eur J Appl Physiol. 2000;82(1-2):61-7.

76. TVEDE N, STEENSBERG J, BASLUND B et al. Cellular immunity in highly trained elite racing cyclist during periods of training with high and low intensity. Scand J Med Sci Sports. 1991;1:163-166.

77. TVEDE N, KAPPEL M, HALKJAER-KRISTENSEN J et al. The effect of light, moderate and severe bicycle exercise on lymphocyte subsets, natural and lymphokine activated killer cells, lymphocyte proliferative response and interleukina-2 production. Int J Sports med. 1993;14: $275-282$.

78. VAN DEN BERGH P, ROZING J, NAGELKERKEN L. Identification of two moieties of beta-endorphin with opposing effects on rat T cell proliferation. Immunology. 1993;79:18-23.

79. WOODS JA. Exercise and neuroendocrine modulation of macrophage function. Int J Sports Med. 1999;20 (5): $322-327$

80. WOODS JA, CEDDIA MA, KOZAK C et al. Effects of exercise on the macrophage MHC II response to inflammation. Int $\mathrm{J}$ Sports Med. 1997;18(6):483-8.

81. WOODS JA, DAVIS JM, KOHUT ML et al. Effects of exercise on macrophage activation for antitumor cytotoxicity. J Appl Physiol. 1994;76: 2177-2185.

82. WOODS JA, DAVIS JM, SMITH JA et al. Exercise and cellular innate immune function. Med Sci Sports Exerc. 1999;31(1): 57-76. 